Hier steht eine Anzeige.

Springer

\section{Darmkrebs mit 35? Plädoyer für Gentest}

Meist wird Darmkrebs erst im höheren Lebensalter diagnostiziert, immerhin $17 \%$ der Fälle aber bei Patienten unter 50 Jahren. Was Patienten charakterisiert, die vor dem 35. Lebensjahr erkranken, haben jetzt USamerikanische Ärzte untersucht.

B etrachtet man alle Patienten mit einem kolorektalen Karzinom, so liegt der Anteil der Patienten mit einem hereditären Syndrom wie dem Lynch-Syndrom (HNPCC, ,hereditary nonpolyposis colorectal cancer") nur bei $2-5 \%$ [Jasperson KW et al. Gastroenterology. 2010;138(6):2044-58]. Ursache dafür sind Mutationen in der Keimbahn.

US-amerikanische Onkologen um Maureen E. Mork haben sich nun die Befunde von fast 200 Patienten an ihrer Klinik genauer angeschaut, die zum Zeitpunkt der Diagnose „Kolorektalkarzinom" höchstens 35 Jahre alt und zwischen 2009 und 2013 genetisch beraten worden waren. Insgesamt 185 von ihnen hatten ein nicht polypöses Karzinom, 20 Patienten den polypösen Phänotyp.

Bei 193 Patienten waren alle Daten komplett und konnten für die Studie verwertet werden. Im Median waren die Patienten 29 Jahre alt, $52 \%$ waren Frauen. 67 von ihnen - also etwa jeder Dritte - hatten ein hereditäres Syndrom, diagnostiziert auf Basis eines positiven Gentests, einer Polyposis oder von Tumoren mit einer MMR-Defizienz („mismatch repair", DNA-Reparaturgen).

In dieser Gruppe wurde unter anderem bei 23 Patienten ein Lynch-Syndrom mit Mutationen in den MMR-Genen diagnostiziert. 22 Patienten hatten ein Lynch-Syndrom ohne pathogenetisch bedeutsame Mutationen und 16 eine familiäre adenomatöse Polyposis (FAP).

Auffallend war, dass Patienten ohne ein hereditäres Karzinomsyndrom eher Metastasen, einen Tumor im linken Kolonabschnitt, wenig differenzierte sowie Siegelring-Tumoren hatten; alles Zeichen für eine aggressive Darmkrebsform. So lag der Anteil der Patienten mit Metastasen in dieser Gruppe bei $56 \%$, in der Vergleichsgruppe bei 28,4\%. Bei Patienten mit hereditärem Karzinomsyndrom war dagegen die Wahrscheinlichkeit für ein frühes Stadium zum Zeitpunkt der Diagnose größer (Tumor-

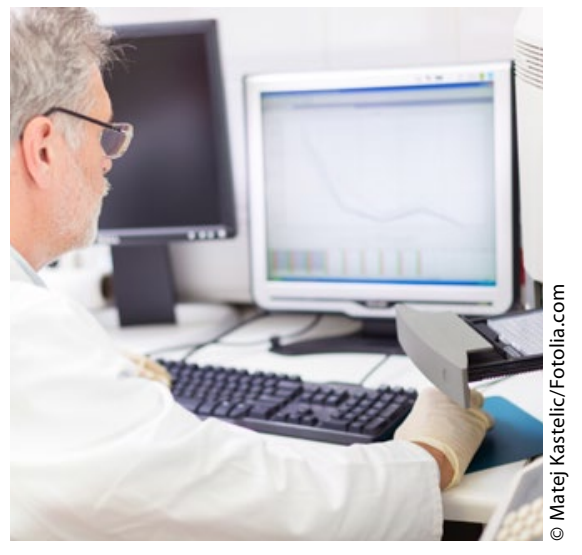

Das Mutationsprofil von Darmtumoren sollte bei unter 35-jährigen Patienten bestimmt werden.

stadium I bzw. II: 11,9 vs. $5,6 \%$ bzw. 16,4 vs. $6,3 \%$ ). Dies galt auch für den Anteil der Patienten mit einer positiven Familienanamnese ( 32,8 vs. $10,3 \%)$.

Erstaunlich war nach Ansicht der Onkologen, dass in der Gruppe der Studienteilnehmer mit hereditärem Karzinomsyndrom 13 Patienten Keimbahnmutationen hatten, aber zugleich eine negative Familienanamnese - also immerhin fast jeder Fünfte. Vermutet wird eine Kombination von ganz neu entstandenen Mutationen und einer inkompletten Genpenetranz.

Fazit: Bei Patienten, die spätestens im Alter von 35 Jahren an einem Kolorektalkarzinom erkranken, ist das hereditäre Karzinomsyndrom offenbar relativ betrachtet viel häufiger als in der gesamten Gruppe der Darmkrebspatienten. Unabhängig von der Familienanamnese halten es die US-amerikanischen Onkologen daher für sinnvoll, Darmkrebspatienten in dieser Altersgruppe genetisch zu beraten.

Peter Leiner

Mork ME et al. High prevalence of hereditary cancer syndromes in adolescents and young adults with colorectal cancer. J Clin Oncol. 2015 Jul 20. [Epub ahead of print]. 